\title{
Sciendo
}

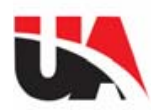

HOLISTICA Vol 10, Issue 3, 2019, pp. 99-110

\section{Starbucks in the World}

\author{
Hui-Jung, CHUANG, \\ CTBC Business School \\ No. 600, Sec. 3, Taijiang Blvd, Annan Dist, Tainan City 709, Taiwan (R.O.C.) \\ 10403039@ctbc.edu.tw
}

\begin{abstract}
Many young people want to work in coffee shops or even open coffee shops, so they set off a wave of entrepreneurship, but according to a survey by the world magazine, Entrepreneurial momentum is strong in Taiwan, and the proportion of entrepreneurship is higher than that of the United Kingdom, Singapore, South Korea, and Japan, second only to the United States, but Taiwan's entrepreneurial "death rate" is also significantly higher than these countries. According to the information of the chief accounting office, Taiwan's entrepreneurship rate was far greater than the rate of business closure before 2000, but after 2000, the chances of successful entrepreneurship fell sharply. Also, many people are used to sipping a cup of coffee in the morning to start a good day. In recent years, the coffee market has developed rapidly in Taiwan, and convenience stores have launched promotional advertisements for cheap coffee. However, we have found that Starbucks, a high-priced coffee brand, has not joined the ranks of cheap coffee. They still maintain their high price and high quality. The most important thing is that we did not see Starbucks ads on any TV commercials or print media. Why did Starbucks not use advertising, but still stand in front of the coffee market?

Starbucks products often seem as a luxury. The most common cup of American coffee costs NT\$100, whereas a cup of coffee at the convenience store costs only NT\$45. Why are so many people willing to pay twice the price? The main reason is the quality and service of Starbucks. Enter into Starbucks, customers can order the beverages without the ice and full of milk, or anything which you want. Customers also enjoy free WIFI in the store, provide mobile phone charging or laptop socket, the staff will serve you with the most enthusiastic attitude. The brand advertise that as long as you ask for what he can do, the partners will meet your needs. In addition, Starbucks products are quite diversified, attracting a large number of consumer groups. From high-quality coffee, decaffeinated beverage juices and Frappuccino, to localized tea drinks in the Greater China region, the needs of every guest are met. Apart from the food, it also sells coffee makers, coffee beans, trendy mobile phone cases that are popular among young people, mobile power supplies, CDs in the store, and mugs and accompanying cups for various themes.
\end{abstract}

Keywords: entrepreneurship, prices, high-quality services.

JEL Classification: M1; P1. 


\section{Introduction}

In 1971, Starbucks opened its first store in Seattle, selling high quality coffee beans and coffee equipment. In the first ten years of its establishment, Starbucks is only a local coffee bean retailer in the Seattle area.

Among them, Starbucks employee Schultz went to Milan on business trip in 1983. When he visited the international furniture exhibition, he encountered the Italian coffee bar, and then indulged in the taste of espresso and the atmosphere in the store. This unforgettable coffee experience gave Schultz the idea of developing an Italian-style coffee chain. After failing to negotiate with the founder, Schultz decided to leave Starbucks in 1985 and opened his first Italian café in the following year. At this point, Starbucks is still a coffee shop retail store with four stores in Seattle. In 1987, Schultz bought Starbucks back and repositioned Starbucks into a chain of cafes, marking the formation of the Starbucks business.

Since 1987, it has been only 30 years since. Starbucks is a young giant and has moved from Seattle to the world over the past three decades, redefining the meaning of coffee retail. Schultz once said," We are not engaged in the coffee industry, but in providing services to customers. We are in the business of customers, coffee is just providing services."

\section{Literature review and background}

When Starbucks went public in 1992, it had 165 chain stores covering only eight cities in the US and Canada: Seattle, Chicago, Vancouver, British Columbia, Portland, Los Angeles, San Francisco, and San Diego. The four states that belong to the United States are Washington, Illinois, Oregon, and California. This shows that Starbucks is still a "regional" company until the market, except for Chicago, which operates only on the west coast of the United States. Don't say that the vast Midwestern region has not yet entered New York, the largest city in the United States. In the early days of development, CEO Schultz chose a strategy of intensive shop opening and deep farming, that is, using a large number of shops to aggressively cover an area. When a large area is spread out, it is considered to expand to the next area or to radiate nearby areas. 
2.1. From the demand side, the "intensive" expansion strategy fits in with Starbucks' early positioning

Schultz insisted on creating the "third space" as the development power of Starbucks. "Third Space" emphasizes Starbucks' community attributes and is an important place for users outside of work and home to socialize. One of the important features is "highly accessible". It is best that people only need to walk to reach Nearby places.

If there are more Starbucks stores in the same area, it will shorten the time customers find any store. Convenience enables consumers to increase the frequency of consumption and thus enhance brand adhesion-the average consumer who is keen on Starbucks in the 1990s visits Starbucks 18 times a month, which is hard to reach for other retailers.

Although this has intensified competition between different single stores in the same region, it can quickly deepen the brand image of Starbucks in the hearts of local consumers. Furthermore, by increasing the density of stores and spreading the flow of customers to other nearby stores, it is possible to reduce the waiting time of each independent store customer and optimize the consumption experience, which is also in line with the essence of Starbucks' "selling service instead of coffee".

2.1.1. From the supply side, the economies of scale in local areas are an important factor in Starbucks' profitability

The main form of the product is brewing beverage, which is easy to operate and easy to achieve standardized production. In other words, as long as the company sets up production in one area, the larger the number of branches, the larger the scale, the lower the fixed expense rate, and the higher the profitability.

Therefore, Starbucks wants to provide standardized and high-quality coffee, which must rely on such expansion mode. At the same time, it can also reduce the company's transportation and management costs.

After the regional model ran through, in line with the listing financing in 1992, Starbucks began to gradually increase the speed of opening stores. The 1990s was the rapid growth of Starbucks in the US market.

Interestingly, the annual average opening speed of Starbucks in the United States in 1993-1997 roughly corresponds to the opening speed of its stores in China in 2010-2014. In 1997, the total number of stores in the United States was 
basically the same as the total number of stores in China in 2014. In China and the United States, Starbucks experienced a similar period of rapid growth.

The timing of this golden period occurred many years after Starbucks began operating in their respective regions (Starbucks entered China in 1999). The creation of an emerging brand, from the cultivation of user cognition to the establishment of a standardized process, requires years of precipitation, but once the explosion comes, it may produce amazing energy.

In addition to the proper macro strategy, Starbucks has shown a lot of excitement in the tactical execution of the early expansion process.

Starbucks' success is largely due to the fact that customers enjoy the service they are satisfied with in the store. Therefore, the operation and improvement of the store has always been an important focus of Starbucks.

Starbucks focused on the high quality and standardization of coffee in the early days. In order to ensure this, based on the intensive expansion strategy, store management is mainly in direct sales and is used in almost all business districts and shopping malls. For some special public places, including airports, university towns, large playgrounds and other crowds, Starbucks has cooperated with them in a franchise manner.

In addition, Starbucks continues to attract retail elites to its senior management, such as appointing professionals with extensive operations and promotion experience in chain stores as regional vice presidents to coordinate regional development and corporate culture migration. And semi-independent store management and expansion mode is implemented on a regional basis.

Specifically, in each target area, Starbucks will set up a central store where a professional team will be deployed to support the center store and the remaining stores in the area, achieving a goal of supporting at least 20 stores in 2 years.

- The way of direct operation is heavier, and the requirements for management and team training are higher.

- Complete grassroots staff training system: A few weeks before entering the new market, Starbucks will recruit local baristas and send senior teams to conduct peer-to-peer training. Ordinary baristas need to receive a total of 24 hours of training, including coffee history, customer service, brewing coffee, retail skills and more.

- Store operations also need to compete for design capabilities: Since 1991 , the company has begun to form its own team of architects and designers to 
ensure that corporate style can run through every store. Because Starbucks does not have the same ownership of each store as McDonald's and Wal-Mart, but leases the existing housing structure, which makes each store in Starbucks different in size and shape. The design of the store needs to be tailored to local conditions.

- Site selection capabilities can be attributed to two key factors: a professional site selection team and a complex set of geographic information systems. Schultz formed a real estate team at the Seattle headquarters to specialize in the location of the coffee industry. According to statistics, Starbucks' early stores are distributed in office buildings, community shopping centers, airports, and university towns in urban or suburban areas, especially in office buildings (business areas) and community centers (shopping areas). Among the two types of stores in the business district and the shopping district, the former is opened at the bottom of the office building, with a high proportion of take-aways and a small storefront. The latter has more factors to consider in the site selection and store design. Starbucks uses GIS (Geographic Information System) data analysis to determine the location and marketing tools. GIS is a system for collecting, storing, processing, analyzing, retrieving and displaying spatial data. Compared with traditional maps and GPS, GIS is more like a database. It collects different data into the database and compares and analyzes it. Traffic, consumer distribution, security information, business composition, and other geographic location information.

\subsection{China Background}

Starbucks, the global chain of coffee giants, opened its first store in Beijing in 1999. With the rise of the middle class and the blessing of the demographic dividend, China has become the second largest market after the United States.

Franchising is a way for many foreign catering brands such as Starbucks and McDonald's to enter China. On the one hand, in the late 1990s, China did not allow foreign-owned enterprises to operate retail and catering businesses; on the other hand, for foreign brands that have just entered the Chinese market, cooperation with local companies facilitates them to penetrate the local market more quickly. The best choice to reduce the risk of off-site transplantation procurement, kitchen control is shared, you only need to export the brand and management system, you can have a certain sales share. 
Starbucks first established a joint venture with two companies: Beijing Meida Coffee Co., Ltd. obtained the agency rights in northern China (Beijing and Tianjin), and the southern region (Hong Kong, Macau, Guangdong, Hainan, Shenzhen, etc.) Hong Kong's Maxim Company obtained.

In May 2000, Starbucks entered Hong Kong and Shanghai, respectively, in Hong Kong's Central Exchange Square, Shanghai Huaihai Road, Lippo Plaza - which means that Starbucks made up its mind to take high-end routes in China from highend shopping malls and office buildings. Business people, white-collar workers began to cultivate the first batch of core users.

However, in China at that time, Beijing's house prices still stayed at 2,000 yuan per square meter, and a cup of cappuccino had a minimum price of 19 yuan. Even few people knew what cappuccino was - to get used to drinking tea. It is too difficult for Chinese consumers to be willing to pay for it. Since the first store opened in Beijing in 1999, Starbucks has lost a full nine years. But managers believe that this is a strategy that can achieve long-term returns, the key is to wait. One day, Chinese consumers will be able to reach a certain income level, and the brand will guide them to form a coffee consumption habit.

Finally, In 2006, 2007 and 2011, Starbucks repurchased the shares of Midea, Sanyuan and Maxim, and directly took over the stores in Central China, North China and South China. Then in 2017, Starbucks throws $\$ 1.3$ billion, and the acquisition of Uni-President Some of the shares have officially taken over 1,300 stores in the East China market, and currently have a total of 3,400 stores in China.

\section{Motivation and Development}

On January 11, 2019, Starbucks, a coffee company from Seattle, entered the Chinese market on the 20th anniversary. Today, the significance of the Chinese market for Starbucks is unquestionable. In terms of performance, same-store sales in the Chinese market have maintained a nine-year growth - despite the first decline in the third quarter of FY18; Starbucks' future development strategy, the Chinese market and digital and high-end brand Starbucks The selection is placed in an equally important position. Right now, it is expanding in China with more than one store per day, creating an average of nearly 10,000 jobs a year. Shanghai Starbucks has more stores than New York, twice as much as the latter. 
SWOT analysis

Strengths

- Starbucks also uses its international status to create itself as a highquality brand. Even though the Chinese are not (and still not) a large coffee consumer, the Starbucks cup quickly became a symbol of status.

- Starbucks calls its employees "partners". Starbucks partners usually have the benefits of free coffee and free partner vouchers. In addition to the statedefined benefits, it also buys serious illness insurance for parents of employees.

Weaknesses

- Its brand image was hit hard in 2013 - consumers found that Starbucks is much more expensive in China than in the US. To make matters worse, it is more expensive to compare on average income: in the United States, the average monthly salary can buy 1,000 cups of latte, but Beijing's average monthly salary can only buy 200 cups.

- For a long time, Starbucks has been criticized for its slow adaptation to the digitalization trend in China; it uses mobile payments later than other brands, and it has only begun to send out until now.

Opportunities

- $\quad$ "Third Space" When Starbucks entered the Chinese market in 1999, its third space strategy resonated with China's emerging middle class. After staying in a crowded office for a long time, they would not return to a narrow apartment.

- Especially popular with the 20-30 age group. As more and more millennials turn to logistics, fewer and fewer customers are seeking third space.

- In 2012, the US company invested in Yunnan to set up a coffee grower support center in Pu'er, Yunnan to support local coffee bean growers, and acquired its approved coffee green beans. Starbucks Yunnan coffee has covered 1,678 farms and 16,000 hectares of coffee. It also promotes coffee beans from Yunnan, similar to the Colombian, Ethiopian and Sumatra coffee that Starbucks has promoted. 
Threats

- In 2018, Luckin Coffee issued an open letter to Starbucks threatening to sue the Seattle-based coffee merchant for violating the trust. Starbucks has become a logistics partnership with Alibaba in the summer. Alibaba has China's second largest food supplier, Ele.me, and some of its 3 million drivers will begin processing orders for Starbucks.

- In May of this year, it honored its promise and sued Starbucks, claiming that Starbucks had deceived the landlord to sign an exclusive lease agreement to prevent competitors from opening stores in areas with Starbucks. Despite this, Rui Xing is still expanding rapidly. Since its inception in January, the café has opened nearly 600 stores in China - Starbucks took 12 years to achieve this.

\subsection{Competitive relationship - Luckin Coffee}

Headquartered in Xiamen, Luckin Coffee is a very young local brand. It was officially put into operation in January 2018. The founder resigned from the position of Shenzhou UCAR Chief Operating Officer to the coffee market. The goal is to replace Starbucks and technology to change consumption habits. The first specific subversion is that Luckin coffee must use mobile phones to place orders. The purpose behind it is to collect customer data extensively, and to match online and offline business practices, to understand customer preferences, the most common time to buy coffee. With the precise marketing methods, such as community call, subsidy and other fast-cutting methods, it has set off a whirlwind in the Chinese business circle.

Luckin Coffee, which is known as the "Little Blue Cup", rose rapidly in a short period of time with crazy subsidies. In January to September 2018, the loss was as high as 857 million yuan (about NT\$3.8 billion), and it was shouted out in 2019. To expand 2,500 new stores, the goal is to surpass Starbucks to become China's largest chain of coffee brands.

But Luckin's coffee shop is different. Starbucks has repeatedly emphasized the comfort level of the store, providing consumers with a "third space" for social activities outside the home or office. Earlier, Starbucks founder Howard Schultz put forward the concept of "third space", which is talked about - the coffee shop is regarded as a social place outside the home and office. In the early days, they were deeply admired by young people who had higher education, had certain 
purchasing power, and demanded social and quality of life. As the group began to accept Starbucks, they began to stand at more levels of consumers. On the contrary, nearly half of Luckin Coffee is a "send to the kitchen", which is specially used to serve online orders and provide delivery. The popularity of Luckin symbolizes the transformation of Chinese consumer culture.

Luckin Coffee is nearly $30 \%$ cheaper than Starbucks and offers discounts such as "Buy 2 Get 1 Free" and "Buy 5 Get 5 Free". Luckin has a cash reserve of 2 billion yuan (290 million US dollars), and the chief executive said that they are "not eager to make money." Compared with cafes, it is more like China's emerging technology companies. Technology is the key to Luckin's success. All of its orders are completed within the app, even in shops where customers can really sit down and relax. They must download the app to complete the order, and then pay through WeChat or Miyuki's own system, without paying cash.

Mobile payment is rapidly becoming the norm in China. In response to this phenomenon, Starbucks cooperated with Alibaba last year, the country's largest online retailer.

\subsection{Starbucks responds to the Chinese consumer market}

- Starbucks delivery kitchen: Starbucks did not say that the new logistics agreement is a response to Luckin, but some of the functions seem to be quite familiar, such as the new "Starbucks delivery kitchen" dedicated to serving online orders. The new program will be tested in Beijing and Shanghai this fall, and will soon expand to other Starbucks locations, minimizing the benefits of Luckin Coffee.

- Create a fourth space: In addition to coffee services, Alibaba will help Starbucks create a more comprehensive online platform that allows customers to purchase goods, order coffee, earn points and pay for a single service. Starbucks calls this digital footprint "the fourth space" and hopes to integrate with the third space to create a collection of online and offline services. Adding online features to existing offline services is much easier than building an entire system from 
scratch, while Starbucks already has 3,400 stores and plans to expand one Chinese store every 15 hours over the next four years.

- Introducing new products: Peanut Mocha Frappuccino, Black Sesame Matcha Frappuccino, Iced Aloe Oriental Beauty Tea... These commonly used ingredients in Chinese catering are creatively added to this American coffee brand.

- Starbucks still found a more gentle way to integrate into the Chinese market. It has increased its investment in China, not only at the commercial level, but also at various aspects behind the store. Sometimes it is not just consumers who want to capture the hearts of the people. Howard was also present at Starbucks' staff meeting in China. Starbucks has also launched a plan to relocate when Starbucks continues to sink into low-end cities, if they open a store in their own hometown.

- In 2012, the US company invested in Yunnan to set up a coffee grower support center in Pu'er, Yunnan to support local coffee bean growers, and acquired its approved coffee green beans. Starbucks Yunnan coffee has covered 1,678 farms and 16,000 hectares of coffee. It also promotes coffee beans from Yunnan, similar to the Colombian, Ethiopian and Sumatra coffee that Starbucks has promoted.

- Connected to WeChat payment and joined Alipay payment in 2016 : Developing WeChat social gift electronic product applet "using the star to say". The membership system has also signed a partnership with Ali to launch a coffee delivery "special star delivery" service. They also quickly expanded their selection of stores in the first-tier cities.

- China's food distribution industry has grown rapidly over the past three years with a market capitalization of nearly $\$ 41$ billion. Competitors seek dominance, squander large sums of money, and offer discount coupons to attract users. In 2017, the market grew by $23 \%$, especially popullared by the $20-30$ age group, which accounted for $70 \%$ of Luckin's business. As more and more millennials turn to logistics, fewer and fewer customers are seeking third space. 
- Change the image: In order to promote the Starbucks WeChat account, they used the story "Our 20-year-old starts with coffee" to tell the story of the 20th anniversary of the brand's entry into China. It seems that this brand is trying to become a young and young boy, full of vigor and dreams.

\section{Discussions and Conclusions}

Starbucks has lost money for nine years and 20 years since it opened its first store in China. With the billion-dollar rivals stepping into the door, Starbucks gradually realized China's changing consumer culture and invited Alibaba as a competent assistant. For foreign retail companies in the Chinese market, Starbucks' success in the Chinese market is worth studying. In the end, It found a moderate and appropriate way to stand, start and accelerate in China.

Once McDonald's and KFC, which are called "junk food", brought Westernstyle fast food to China, Walmart relies on the concept of "low price" to let people accept the mode of hypermarket. Coca-Cola invested heavily in China and eventually sold its own bottling business. The third coffee trend pursuing coffee aesthetics is gradually sprouting and launching a shock to chain coffee shops. The boutique coffee brands such as \%Arabica enter the Chinese market, and local boutique coffee shops are also emerging.

The emergence of Lukin Coffee, even coffee and other coffee delivery "spoilers", along with the convenience brought by digital life to consumers, also let the once high Starbucks began to try to embrace e-commerce and various online platforms. Under the rush of take-away coffee from Luckin, Starbucks has also accelerated its plan to launch a takeaway service, working with Alibaba on a platform that is hungry.

However, the expansion challenge that Starbucks faces in China today is different from today. Starbucks, once in the hearts of Chinese consumers, is now more eager to connect with consumers to continue to maintain an appeal. It's not easy to beat Starbucks. Starbucks has 3,400 stores in more than 140 cities across China, and plans to double that number by 2022. 


\section{HOLISTICA Vol 10, Issue 3, 2019}

\section{References}

[1] https://money.udn.com/money/story/6709/3691213

[2] https://www.managertoday.com.tw/articles/view/54797

[3] https://www.bnext.com.tw/article/46651/company-stories-starbucks

[4] http://www.guojicoffee.com/ppgs/6794.html

[5] https://www.bnext.com.tw/article/46651/company-stories-starbucks

[6]https://www.newsmax.com/finance/benreynolds/starbucks-global-expansionpercolating/2018/10/01/id/884301/

[7]https://www.forbes.com/sites/pamelaambler/2019/03/13/starbucks-accelerates-expansionacross-asia-amid-intensifying-competition/

[8] https://www.thenewslens.com/feature/timefortune/103101

[9] https://www.storm.mg/lifestyle/796853. 